\title{
RESPONSIVITAS KEBIJAKAN LOKAL DALAM MENGHADAPI DINAMIKA SOSIAL
}

\author{
Wayan Joniarta \\ Universitas Pendidikan Nasional \\ joniarta_12345@yahoo.com
}

\begin{abstract}
ABSTRAK
Patut diakui bahwa terdapat sistem ganda dalam pemerintahan desa yaitu desa dinas dan desa pakraman. Desa Pakraman di Bali merupakan sebutan lain dari desa adat, yang telah mengakar sejak lama. Seiring bergulirnya reformasi yang dimulai tahun 1998, desa pakraman diperkuat oleh Peraturan Daerah Nomor 3 tahun 2001 tentang desa pakraman. Teriring semangat UU No. 32 tahun 2004 tentang pemerintahan daerah dan juga hasil amandemen UUD 1945 pasal 18 b ayat (2) dengan tegas telah memberikan peluang untuk membangkitkan atau menghidupkan kembali otonomi asli dalam penyelenggaraan pemerintahan di tingkat desa. Bekat dualisme desa berarti dilihat dari sisi kebijakan maka desa dinas berada pada konteks kebijakan nasional dan desa adat/pakraman berada pada konteks kebijakan tradisional. Tulisan ini mendeskripsikan secara aktual tentang fakta keberadaan desa pakraman, bahwa sesungguhnya desa pakraman yang mempunyai hak otonum dalam kaitan dengan adat istadat dan budaya, namun keluesan, kejujuan, fleksibilitas orang Bali terkadang ternodai oleh tindakan anarkis, seperti terjadinya kasepekang terhadap warga di Desa Pakraman akibat dari kurang aktifnya warga tertentu dalam kegiatan adat istiadat. Disamping itu desa pakraman sebenarnya terbebani untuk merespons isu - isu yang sebenarnya merupakan kewenangan dari pemerintah supra local, seperti masalah narkoba, pungli, rabies, KIPEM dan isu hangat lainnya.
\end{abstract}

Kata Kunci: : Kebijakan lokal, Dinamika Sosial

\begin{abstract}
It should be recognized that there is a dual system in the village government, namely the official village and pakraman village. Pakraman village in Bali is another name for a traditional village, which has been rooted for a long time. As the reformation began in 1998, Pakraman village was strengthened by Regional Regulation No. 3 of 2001 concerning Pakraman village. With the spirit of Law No. 32 of 2004 concerning regional government and also the results of amendments to the 1945 Constitution article 18 b paragraph (2) have explicitly provided an opportunity to revive or revive original autonomy in the administration of government at the village level. The
\end{abstract}


dualism of the village means that in terms of policy, the official village is in the context of national policies and traditional villages / pakraman in the context of traditional policies. This paper actually describes the fact of the existence of Pakraman village, that in fact Pakraman village has otonum rights in relation to customs and culture, but the flexibility, purpose, flexibility of Balinese people is sometimes tarnished by anarchist actions, such as the occurrence of kasepekang for residents in Pakraman Village due to from the inactivity of certain citizens in customs activities. Besides that Pakraman village is actually burdened to respond to issues that are actually the authority of the supra-local government, such as the problem of drugs, extortion, rabies, KIPEM and other important issues.

Keyword : Local Policy, Social Dynamics

\section{Pendahuluan}

Bali sebagi salah satu pulau yang ada di Indonesia bukan hanya memiliki desa dinas seperti yang tersirat pada UU No 5 tahun 1979, tetapi ada desa adat (pakraman) yang telah ada sejak jaman dulu. Keadaan tersebut didukung penjelasan pasal 18 khususnya bagian II UUD 1945 bahwa "Dalam teritoir Negara Republik Indonesia terdapat lebih kurang 250 zefbestuurlandschappen dan volkggemeenschappen seperti desa di Jawa dan Bali...Daerahdaerah itu mempunyai susunan asli, dan oleh karenanya dapat dianggap sebagai daerah yang bersifat istimewa". Keberadaan masing-masing bentuk desa tersebut sampai saat ini tetap dipertahankan, sehingga sekarang ini masih terjadi dualisme desa. I Gde Pariartha (Sudantra, 2007) menyebut "sistem ganda dalam pemerintahan desa, adanya desa pakraman berdampingan dengan desa dinas"

Selama pemerintahan Era Orde Baru yang cendrung menterapkan sistem sentralisasi. Surbakti yang dikutip oleh Subanda ( 2007 :1) mengatakan "kekuasaan yang besar dengan sistem pemerintahan yang sangat sentralistik dan birokratis paling menonjol terlihat pada jaman Orda Baru". Hal tersebut bukannya tanpa alasan, diungkapkan oleh Budiman ( Subanda, 2007 :1 ) bahwa "istilah-istilah demi kepentingan umum, pembagunan nasional untuk segala lapisan masyarakat biasanya dipergunakan sebagai pembenaran terhadap kekuasaan negara untuk memaksa seseorang atau kelompok warga negara agar bersedia mematuhi keinginan negara". Bila dicermati secara mendalam, selama pemerintahan Orda Baru tampaknya upaya pemerintah untuk menyeragamkan sistem pemerintahan yang sentralistik diperkuat dan dipertahankan terus 
seiring dengan dikeluarkannya Undang-Undang Nomor 5 tahun 1979 mengenai Pemerintahan Desa. Mengintisarikan pandangan Sudantra (2007). bahwa "dalam konteks Undang-Undang Nomor 5 tahun 1979 “......desa sebagai wilayah $\backslash$ administrasi di bawah kecamatan dengan bentuk dan susunan yang seragam di bawah kecamatan".Berarti birokrasi pemerintah cukup menentukan dalam tingkat desa, apalagi jabatan-jabatan pada level desa cendrung menjadi jabatan birokratis. Hal tersebut kemungkinan menjadi alasan bahwa sistem sentralisasi tetap bertahan dan diterima, artinya "dalam memberikan respon terhadap sentralisasi dan birokratisasi pemerintah, rakyat di Bali pada umumnya tidak melakukannya dengan penolakan atau perlawanan, melainkan dengan mengakomodasi kebijaksanaan pemerintah tersebut....".(Warren dalan Subanda, $2007: 1$ ).

Sejak bergulirnya reformasi yang dimulai pada tahun 1998 berbagai perubahan terus terjadi. Eko Prasojo (2012 : 1) menyebutkan "Monentum reformasi tahun 1998 tidak hanya berkorelasi terhadap perubahan birokrasi, tetapi juga berdampak terhadap sistem pemerintahan dan hubungan pusat - daerah dengan diterapkannya asas desentralisasi “. Ungkapan yang lebih menukik, menurut Holidin,dkk (2016:2) menyatakan "Reformasi dewasa ini tidak hanya diterapkan lingkungan pemerintah (pusat) tetapi juga diikuti, bahkan pada kebanyakan kasus, justru dirintis oleh sejumlah pemerinahan sub nasional dan lokal di Indonesia melalui programprogram inovasi sektor publik sebagai upaya reformasi birokrasi". Akibat dari diterapkannya asas desentralisasi, diiringi dengan pemberian otonomi daerah sehingga berdampak pada jiwa optimisme dikalangan elit politik daerah untuk berkiprah, karena tuntutan otonomi daerah mulai mendapatkan angin segar setelah begitu lama menjadi idaman daerah atas asas desentralisasi. Dalam aspek tertentu tuntutan akan asas dersentralisasi tidaklah berlebihan, bahkan mengandung suatu kebenaran. Mengapa demikian? Ada kecendrungan beberapa kalangan sepakat bahwa "tujuan dari otonomi daerah tidak lain adalah untuk mendekatkan locus pengambilan keputusan pada level pemerintahan yang paling dekat dengan masyarakat (prinsip subsidiaritas). Disamping itu jangkauan pelayanan menjadi lebih efisien dan efektif karena span of control menjadi lebih kecil”(Eko Prasojo,dkk, 2012 :2). Dalam pada itu, "semangat UU No. 32 tahun 2004 tentang pemerintahan daerah dan juga hasil amandemen UUD 1945 pasal 18 b ayat (2) 
dengan tegas telah memberikan peluang untuk membangkitkan atau menghidupkan kembali otonomi asli dalam penyelenggaraan pemerintahan di tingkat desa" (Suacana, 26 Maret 2009).

Menarik untuk dicermati karena desa pakraman di Bali sebenarnya sudah mengakar amat lama dimasyarakat Bali, dan diperkuat oleh Peraturan Daerah Nomor 3 tahun 2001 tentang desa pakraman. Sebutan Desa Pakraman, merupakan istilah sebelumnya disebut Desa Adat. Ungkapan tersebut didukung dalam penjelasan Perda tersebut, istilah "pakraman" telah dipergunakan sejak adanya desa di Bali” (penjelasan umum Peraturan Darerah Provinsi Bali No. 3 tahun 2001). Ini berarti sejak dulu istilah desa pakraman sudah menjadi milik Bali, ada kecendrungan istilah tersebut digunakan untuk mengingat dan melestarikan warisan leluhur Bali. Dasar pertimbangan diangkatnya desa pakraman sebagai focus penelitian karena "Desa Pakraman di propinsi Bali tumbuh dan berkembang sepanjang sejarah selama berabad-abad, yang memiliki daerah otonomi asli mengatur rumah tangganya sendiri, telah memberikan kontribsi yang sangat berharga terhadap kelangsungan kehidupan bermasyarakat dan pembangunan" (Peraturan Darerah Provinsi Bali No. 3 tahun 2001). Karena dengan keluarnya Peraturan Daerah Nomor 3 tahun 2001 ada kecendrungan berimplikasi terhadap aspek-aspek yang lain. Subanda dalam Jurnal Opini (2007) menyebutkan "besarnya kewenangan yang diberikan pemerintah supra local...akan berdampak terhadap menguatnya kekuasaan desa adat, dan akhirnya dapat pula menimbulkan dilema dan permasalahan baru”. Selanjutnya Dwipayana dikutip oleh Subanda (Jurnal Opini, 2007) menegaskan "desa adat bisa bertindak otoriter terhadap kebebasan individu dan sejumlah warga minoritas". Suacana (Jurnal Ilmu Politik, 2010 : 137-154) menyebutkan "Desa di Bali khususnya desa adat/pakraman sering dipersepsikan sebagai sebuah lembaga non formal yang relative demokratis dan otonom sehingga sama sekali merdeka dari kekuatan lain diluarnya" Selain ini bisa saja akan bermunculan permasalahan baru, termasuk perkembangan politik terkadang sulit dihindari oleh desa pakraman.

Mencermati situasi saat ini, dengan dualisme desa berarti dilihat dari sisi kebijakan maka desa dinas berada pada konteks kebijakan nasional dan desa adat/pakraman berada pada konteks kebijakan tradisional. Namun ada kecendrungan terjadinya tumpang tindih baik dari segi kewilayahan maupun keberadaan krama desa. Pitana dikutif oleh Arya Sunul dkk (2014) menyatakan "ada kemungkinan antara lain: (1) satu desa dinas mempunyai luas wilayah dan penduduk yang sama dengan satu desa pakraman, (2) satu desa dinas meliputi beberapa desa 
pakraman, (3) satu desa pakraman, terdiri atas beberapa desa dinas, (4) satu desa dinas meliputi beberapa desa pakraman dan sebagian dari desa pakraman lain"

- Perlu dipahami bahwa masyarakat Bali mempunyai ciri khas yang menonjol dimana setiap aktivitasnya cendrung selaras dengan ajaran agama Hindu dan kehidupan adat dan budaya Bali, dan bertumpu pada konsep Tri Hita Karana. Bali sebagai bagian dari wilayah Indonesia dalam membangun hendaknya tetap menjunjung tinggi nilai-nilai budaya dan adat istiadat yang merupakan bagian dari nilai kearifan lokal Bali. Namun yang patut diccrmati keunikan dari masyarakat Bali ibarat dua sisi mata uang yaitu disatu sisi mengikuti kebijakan nasional, disisi lain tanpa mengabaikan kebijakan yang telah diwarisi dari nenek moyangnya secara turun temurun sesuai adat dan budaya Bali.

Kondisi dilematis di ataslah responsivitas kebijakan lokal perspektif otonomi desa pakraman menjadi amat penting untuk dicermati dan dikaji. Adapun alasannya adalah seperti diperkuat oleh pernyataan Budi Rajab dalam Joniarta (jurnal Opini Vol.8. N0.1 Pebruari 2011) menyatakan "pemerintah yang baik (good government) adalah pemerintah yang responsif dalam upaya memecahkan ragam masalah yang dihadapi masyarakatnya". Pernyataan tersebut sepertinya layak diadopsi walaupun tulisan ini membahas tentang kebijakan local namum tetap saja ada unsur kebijakan dan masyarakat sebagai sasaran kebijakan tersebut. Disamping itu hendaknya tetap diakui setiap kesatuan masyarakat yang berada dibawah Negara tidak bisa lepas dari kekuasaan supra nasional.

Berdasarkan uraian latar belakang di atas melalui tulisan ini ingin mencermati salah satu kearifan lokal Bali yaitu berkaitan dengan "responsivitas kebijakan lokal dalam menghadapi isu global (perspektif otonomi desa pakraman di Bali)". Tulisan ini terfokus bukan pada pengukuran baik secara kualitatif maupun kuantitatif, tetapi mendeskripsikan dan menjelaskan secara aktual, faktual mengenai keberadaan desa pakraman dalam menghadapi isu-isu yang besifat global. 


\section{Kajian Teori}

Tulisanini akan memaparkan beberapa konsep yang berhubungan dengan topik yang diangkat yaitu : konsep responsivitas, kebijakan lokal, desa pakraman.

1. Responsivitas. Jika hendak ditafsirkan secara bebas responsivitas dapat diartikan daya tanggap. Menyitir istilah yang sering muncul dalam membahas birokrasi, dikatakan bahwa "Secara singkat dapat dikatakan bahwa responsivitas ini mengukur daya tanggap birokasi terhadap harapan,keinginan dan aspirasi,serta tuntutan masyarakat"(Tangkilisan,2005:177). Selanjutnya "Responsivitas adalah kemampuan provider untuk mengenali kebutuhan masyarakat, menyusun agenda dan prioritas pelayanan sesuai dengan kebutuhan dan aspirasi masyarakat. Secara singkat dapat dikatakan bahwa responsivitas itu mengukur daya tanggap provider terhadap harapan, keinginan dan aspirasi serta tuntutan customer "(Ratminto \& Atik Septi Winarsih, 2005 : 180-181). Telah diungkapkan bahwa "organisasi yang memiliki responsivitas rendah dengan sendirinya memiliki kinerja yang jelek juga" (Osborne \& Plastrik, 1997).

2.Kebijakan Lokal. Bila mencermati difinisi kebijakan kecendrungannya dapat membingungkan, apalagi setiap ahli menyampaikannya dengan persinya yang berbeda. Dalam penelitian ini akan berusaha untuk menggali konsep, pengertian dan definisi kebijakan yang tidak jauh berbeda dengan permasalahan penelitian ini. Frederick dalam Agustino (2008: 7) menyatakan "kebijakan sebagai serangkaian tindakan / kegiatan yang diusulkan seseorang, kelompok atau pemerintah dalam suatu lingkungan tertentu dimana terdapat hambatan-hambatan (kesulitan-kesulitan) dan kesempatan-kesempatan terhadap pelaksanaan usulan kebijaksanaan tersebut dalam rangka mencapai tujuan tertentu". Dipihak lain Persons (Redit, 2016 : 6) menyatakan "kebijakan adalah perangkat aksi atau rencana yang mengandung tujuan politik".

Selanjutnya Nurchollis (2007 : 263) mengemukakan bsahwa "kebijakan sebagai keputusan organisasi.......berisikan ketentuan-ketentuan yang dapat dijadikan pedoman perilaku dalam : a) pengambilan keputusan lebih lanjut, yang harus dilakukan baik kelompok sasaran ataupun unit organisasi pelaksana kebijakan. b) penerapan atau pelaksanaan dari suatu kebijakan yang telah diterapkan baik dalam hubungan dengan unit organisasi pelaksana maupun dengan kelompok sasaran yang dimaksud". Mencermati pernyataan-pernyataan di atas, dapat dipahami 
bahwa kebijakan mengandung beberapa prinsip yaitu : a) kebijakan mencakup serangkaian tindakan yang diusulkan oleh seseorang atau kelompok dalam suatu lingkungan teretentu. b\} mengandung tujuan yang bersifat politik, c) Ketentuan yang dapat dipakai sebagai pedoman perilaku. d) terdapat kelompok sasaran, e) Terdapat hambatan-hambatan dalam mencapai tujuan. f) Ada kesempatan untuk usulan kebijakan baru.

3. Desa Pakraman. Kata desa seperti yang dikatakan oleh Soetarjo Kartohadikoesomo (Subanda,2013) berasal dari kata sansekerta yang berarti tana air, tanah asal atau tanah kelahiran" Selanjutnya "desa adat sekarang disebut desa pakraman" (Soekarno dalam Subanda, 2013). Pada penjelasan umum (4) Peraturan Daerah Nomor 3 tahun 2001 menyebutkan "desa pakraman adalah suatu kesatuan masyarakat hukum yang mempunyai susunan asli,hak asal usul yang bersifat istimewa bersumber pada agama Hindu, Kebudayaan Bali, berdasarkan TriHita Karana, mempunyai kahyangan tiga/kahyangan desa. Landasan pemikiran dalam pengaturan mengenai desa pakraman adalah keaneka-ragaman, partisipasi,otonomi asli,demokratisasi dan pemberdayaan krama desa.

\section{Pembahasan}

Penduduk Bali terkenal keramah tamahannya, kejujuran, menjunjung keharmonisan justru diwarnai dinamika yang cendrung menciderai konsep Tri Hita Karana. Seiring pandangan Atmaja (Subanda, 2013) menyatakan bahwa "walaupun berkembangnya masyarakat multicultural, di Bali telah berpegang dan dilandasi dengan kesadaran Bhneka Tunggal Ika namun dalam kenyataannya terjadi diferensiasi social yang mengarah pada polarisasi sehingga konflik sulit dihindarkan”.

1. Melekatnya Konsep Rwa Bineda

Ironisnya tampak dari mencuatnya konflik yang bernuansa adat yang bersifat anarkis. Hasil penelitian Arya Sunul, dkk (2014) menyebutkan "Kini, entah mengapa, kesantunan itu berubah menjadi beringas, gelap mata serta anarkis. Latar belakang terjadinya kasepekang terhadap warga di Desa Pakraman Tusan adalah masalah "adat". Kasus kesepekang kembali terjadi, kali ini menimpa seorang warga Kedungu Tabanan, yang disebabkan oleh perlakuan menodai tempat suci”. Dapat dikatakan sesuatu yang 
diluar nalar, dimana masyarakat Bali yang dikenal luwes, santun, fleksibel dan halus justru menterapkan suatu sangsi yang kurang manusiawi.

Fenomena lainnya yang sering muncul kepermukaan desa pakraman yaitu kaitan antara krama wed (penduduk asli) dan krama tamiu (penduduk pendatang). Patut diakui bahwa orang Bali mengenal konsep rwa bineda yaitu dua unsur yang berlawanan. Seperti dikemukakan oleh Fay dalam Atmadja ( Arya Sunul dkk, 2014) mengatakan "dualisme dikotomik bisa mendorong terjadinya suatu pertentangan antara dua entitas dan kekuatan yang harus dipilih keberpihakannya, yakni pihak ini atau pihak itu. Bersamaan dengan itu, konflik yang semula bersifat perebutan sumber daya ekonomi maupun politik bisa berubah menjadi konflik antara kita dan mereka, muwed dan tamiu, atau Bali melawan etnik non-Bali”. Selanjutnya Miall dalam Pageh (Arya Sunul dkk, 2014) menyatakan "Namun, sering konflik dianggap sebagai patologi sosial, padahal jika dikelola dengan baik bisa menjadi kekuatan pembangunan bangsa. Bila dicermati konflik dapat terjad secara internal (diantara warga desa pakraman).

Melalui tulisan ini mengangkat kasus yang terjadi di Desa Pakraman Marga, perarem menggariskan bahwa krama yang bertempat tinggal tetap di wilayah desa pakraman wajib menjadi krama desa pakraman tersebut. Tetapi ada beberapa keluarga yang menolak karena dari dulu orang tuanya tercatat secara administratif diluar desa pakraman tersebut. Dampaknya bila ada hajatan atau upacara agama mereka cendrung tidak mendapatkan pelayanan seperti krama yang telah tercatat sebagai krama desa. Disinilah muncul konflik disatu sisi mereka yang tak dapat pelayanan mengeluarkan kata-kata " saya dikeluarkan sebagai krama desa ini tak apa-apa". Tetapi dalam hal tertentu sebenarnya mereka ikut menikmati pelayanan desa pakraman. Hal tersebut berpengaruh pada konflik ekstrenal (konlik antar desa pakraman). Dimana desa yang menerima krama yang tak tercatat tadi sebagai karma desanya.

2.Isu Publik Sebagai Pemicu Lahirnya Kebijakan Lokal

Patut dikagumi bahwa desa pakraman di Bali yang terkenal dengan sistem banjar menjadi contoh untuk Bali. Seperti dikatakan Kepala Dinas Pemberdayaan Masyarakat dan Desa Pemprov Bali Lihadnyana (Tribun Bal-.Com. 17 Agustus 2017) bahwa "kita lihat contoh lembaga seperti desa pakraman, banjar adat itu efektif dan sudah menjadi 
contoh sistem banjar contoh terbaik di Bali misalnya dalam menjalankan program KB. Ini diperluas peran banjar untuk juga berperan aktif menanggulangi narkoba, ujarnya terpisah". Selanjutnya disebutkan bahwa Bali yang terdiri dari 1.488 desa pakraman memiliki awig-awig (aturan desa secara adat Bali), namun sebagian besar di dalam awigawig desa pakraman belum mencantumkan kebijakan desa untuk berperan aktif melawan narkoba. Dalam konteks ini wewenang pemerintah supra - local tampaknya ada kecendrungan pembentukan perda yang nantinya menekankan agar desa pakraman membuat perarem (aturan teknis dari awig-awig) yang mencantumkan sangsi adat berupa sangsi sosial bagi mereka yang melanggar perarem dimaksud.

Tertib administrasi kependudukan biasanya wewenang dari desa dinas, tetapi dengan diefektifkannya otonomi desa pakraman pendataan dan penertiban penduduk cendrung dilakukan oleh desa pakraman dengan berkoordinasi dengan desa dinas. Uniknya desa pakraman membentuk perarem desa pakraman. Sebagai contoh berlangsung di Kecamatan Kota Tabanan "jumlah pemilik kost sekitar 250 orang. Pada saat pemeriksaan identitas Camat Tabanan (Putu Arya Suta) memperkirakan sekitar 1.500 penduduk pendatang sebelum arus mudik 2017". Berkenaan dengan itu "kota Tabanan sebagai percontohan, juga mendapatkan support dari pihak kepolisian saat pengesahan perarem desa adat kota Tabanan" (Argawa, 2017)

\section{Kesimpulan}

Desa pakraman yang memiliki otonomi diantaranya menertibkan dan mengaktifkan kemabali kegiatan adat, menghidupkan dan menguatkan kembali sanksi-sanksi adat seperti sesepekang bila tidak aktif dalam kegiatan adat, dilarang mengubur mayat, namun disisi lain terbebani dengan membuat kebijakan (perarem) yang sebenarnya merupakan wewenang pemerintah supra-lokal seperti Gubernur, Bupati, sehingga desa pakraman sering dilibatkan dalam penataan administrasi kependudukan, penertiban pasar, penertiban lalu lintas (oleh pecalang), pengamanan kongres partai politik. Bahkan pembuatan peraren tentang rabies, narkoba,pungli, flu burung, kipem, dan isu-isu uptudate lainnya. Desa Pakraman di Bali tampaknya mempunai kontribusi yang perlu diacungkan jempol, karena dalam kesibukannya 
mengurus adat dan budaya yang cukup kompleks masih mampu mengurus hal-hal yang sebenarnya wewenang pemerintah supra lokal.

\section{Daftar Pustaka}

Agustini, Leo. 2008. Dasar-Dasar Kebijakan Publik, Bandung: Alfabeta.

Arifin, Zaenal. PERILAKU KEPEMIMPINAN TRADISIONAL PESANTREN, Jurnal Kepemimpinan Tradisional Pesantren Volume 24 Nomor 2 September 2013.

Arya Sunul, I Gusti Ketut, Harmonisasi Integrasi Desa Pakraman Dengan Desa Dinas Yang Multietnik dan Multiagama Menghadapi Pergeseran, Pelestarian, dan Konflik di Bali. Jurnal Ilmu Sosial dan Humanihora. ISSN : 2303-2898 Vol.3,No 2 Oktober 2014.

Argawa, I Made. Kipem telah dilarang, desa adat ini keluarkan perarem, Tribun Bali, 11 Juli 2017.

Budiardjo Miriam. 2013. Dasar-Dasar Ilmu Politik. Edisi Revisi. Jakarta: PT Gramedia Pustaka Utama.

Faisal. NILAI-NILAI KEPEMIMPINAN TRADISIONAL DALAM KOMUNITAS ADAT KAJANG DI SULAWESI SELATAN (majalah WALASUJI Volume 6, No. 1, Juni 2015: 17-30).

Joniarta, I Wayan, Murdita, Putu . Analisis Respons Masyarakat Terhadap Pelayanan Polsek Kerambitan Kabupaten Tabanan ( Jurnal Opini,Vol 8.No. 1 Pebruari 2011).

Nurcholis, Hafin, 2007. Teori dan Praktek Pemerintahan dan Otonomi Daerah. Jakarta: PT Gramedia Widiasarana Indonesia.

Pageh, I Made, 26 November 2015. Makalah “Kepemimpinan Dalam Perspektif SosiaoKultural".

Ratminto, Atik Septi Winarsih. 2015. Manajemen Pelayanan. Jogyakarta: Pustaka Pelajar. 
Redit, I Wayan. Skripsi Kebijakan Pemerintah Mengenai Geopark (Analisis Implekasi Kebijakan Geopark di Desa Batur Tengah Kabupaten Bangli.

Subanda. Mediasi Dan Solusi Konflik Adat di Bali Melalui Majelis Desa Pakraman. Jurnal Dialog Kebijakan Publik. Edisi 11 September 2013.

Subanda. Jurnal Opini Vol. 4 N0.1 Pebruari 2007. Negara, Desa Adat dan Rakyat Dalam Kepemimpinan Lokal di Bali.

Sarundajang. 1998. Ants Balik Kekuasaan Pusat Ke Daerah. Jakarta: Pustaka Sinar Harapan.

Suacana, I Wayan Gede. 2009. Otonomi Daerah Dan Eksistensi Desa Pakraman di Bali.

Suacana,I Wayan Gede. Transformasi Otonomi Dalam Tata Pemerintahan Desa Mengwi Kabupaten Badung (Jurnal Ilmu Politik edisi 21 2010, halaman 137-14), penerbit Kerjasama AIPI dengan Pustaka Pelajar.

Subanda, I Nyoman, dkk. 2007. Laporan Hasil Penelitian : Negara Desa Adat dan Rakyat Dalam Kepemimpinan Lokal di Bali (Universitas Pendidikan Tangkilisan, Hessel Nogi. 2005. Manajemen Publik. Jakarta Nasional Denpasar: PT Gramedia Widiasarana Indonesia).

Lihadnyana, Ketut (Kepala Dinas Pemberdayaan Masyarakat dan Desa Pemprov Bali) "Darurat Narkoba? 1.488 Desa Diminta Bentuk Perarem Narkoba, Tribun Bali-com. 22 Agustus 2017. 